\title{
ST6GalNAcII mediates tumor invasion through PI3K/Akt/NF-кB signaling pathway in follicular thyroid carcinoma
}

\author{
XIAOLONG $\mathrm{MIAO}^{1}$ and YONGFU $\mathrm{ZHAO}^{2}$ \\ ${ }^{1}$ Department of General Surgery, Dalian Medical University, Liaoning; ${ }^{2}$ Department of General Surgery, \\ The Second Affiliated Hospital of Dalian Medical University, Liaoning, P.R. China
}

Received November 8, 2015; Accepted December 17, 2015

DOI: $10.3892 /$ or.2016.4590

\begin{abstract}
Altered sialylation, closely associated with tumor progression and metastasis, has been implicated in human thyroid carcinoma. The present study investigated the alteration in expression of ST6GalNAcII involved in invasion and to clarify the possible mechanism of ST6GalNAcII in the metastasis process in human follicular thyroid carcinoma cell lines. Using real-time PCR, western blot and IHC analysis, ST6GalNAcII differed in three follicular thyroid cancer cell lines (FTC133, primary and FTC238, lung metastasis). It also showed differential expression in follicular thyroid carcinoma and tissue specimens. In addition, we analyzed the PI3K/Akt signaling pathway. The altered expression of ST6GalNAcII corresponded to changed invasive phenotype of FTC-238 and FTC-133 cells in vitro and in vivo. Further studies showed that regulating ST6GalNAcII expression markedly modulated the activity of the phosphoinositide 3-kinase (PI3K)/Akt signaling pathway. Targeting the PI3K/Akt pathway by its specific inhibitor LY294002, or by Akt small interfering RNA (siRNA) resulted in reduced capacity in invasion of FTC-238. In conclusion, taken together, our results imply that ST6GalNAcII activated the invasion in follicular thyroid cancer cells through regulating the activity of PI3K/Akt pathway.
\end{abstract}

\section{Introduction}

Thyroid cancers are the most common malignant tumors of the endocrine system. Metastasis of tumor cells frequently contributes to the failure of treatments in patients diagnosed with thyroid cancer. Substantial research has been devoted

Correspondence to: Professor Yongfu Zhao, Department of General Surgery, The Second Affiliated Hospital of Dalian Medical University, 465 Zhongshan Road, Dalian, Liaoning 116027, P.R. China

E-mail: zyf0386@sina.com

Key words: ST6GalNAcII, invasive properties, follicular thyroid carcinoma, PI3K/AKt signaling to elaborating the relationship between glycan alterations and invasive properties of malignant cells. The changes of glycans on cell glycoproteins play a physiological role in regulating metastatic efficiency of tumor cells (1). It is known that alteration in cell surface sialylated antigens affects many cellular properties (2-5). Sialyltransferases, a subset of glycosyltransferases, have been recognized to be involved in various diseases by catalyzing the biosynthesis of different glycoconjugates and saccharide structures (6). They use CMP-Neu5Ac as an activated sugar donor to catalyze the transfer of sialic acid residues to terminal positions of glycoprotein and glycolipid carbohydrate groups (7).

Sialyltransferases (ST) are a group of enzymes responsible for the transfer of sialic acid from cytidine 5-prime monophospho-N-acetylneuraminic acid (CMP-NeuAc) to terminal positions of glycoprotein and glycolipid carbohydrate groups. ST consisting of 20 members that are subjected into three subfamilies: $\alpha-2,3$-sialyltransferases, $\alpha$-2, 6 -sialyltransferases, $\alpha$-2, 8-sialyltransferases (8). $\alpha$-2, 6 -sialyltransferases mediate the transfer of sialic acid with an $\alpha$-2, 6-linkage to it with terminal Gal (ST6Gal 1-2) (9) or GalNAc residues (ST6GalNAc 1-6). Changes in specific ST6GalNAc family expression have been reported to be altered in several tumors. High level of ST6GalNAcI expression was associated with the tumorigenicity of MDA-MB-231 breast cancer cells (10). Suppression of ST6GalNAcII mRNA is not only associated with the pathological phenotype of IgA nephropathy but also with the poor prognosis in IgA nephropathy patients $(11,12)$. ST6GalNAcIV promotes lung cancer metastasis through adhesion to galectins (13). ST6GalNAc V plays a positive role in mediating brain metastasis of breast cancer cells (14).

The phosphatidylinositol-3-kinase (PI3K)/Akt pathway is one of the core intracellular signaling pathways, it plays a crucial role in many cellular processes including proliferation, differentiation, apoptosis, cell cycle progression, cell motility and tumorigenesis, tumor growth, angiogenesis $(15,16)$. Furthermore, aberrant activation of PI3K/Akt pathway has been reported to be a significant indicator of proliferation, invasion, metastasis in thyroid cancer. Activation of PI3K/ AKT/mTOR pathway sustains malignant features of MTC cell models (17). The proliferation and invasion of thyroid cancer cells are inhibited by curcumin via downregulation of PI3K/ Akt signaling pathway (18). However, it remained largely unknown whether there is a certain correlation between 
ST6GalNAcII and PI3K/Akt pathway in the progression of invasion, metastasis in thyroid cancer.

Therefore, we undertook to characterize the expression of ST6GalNAcII in FTC-238 and FTC-133 cell lines and thyroid cancer tissue samples. Besides, we investigated the correlation between ST6GalNAcII and PI3K/Akt pathway and their role in the thyroid cancer metastasis.

\section{Materials and methods}

Cell culture and tissues. Human follicular thyroid carcinoma cell lines FTC-133 and FTC-238 were purchased from Guangzhou Jennio Biotech Co. (China). The cell lines were grown in Dulbecco's modified Eagle's medium(DMEM)/Ham's F12 medium containing $2 \mathrm{mM}$ glutamine, $10 \%$ fetal bovine serum (FBS), $100 \mathrm{U} / \mathrm{ml}$ penicillin, and $100 \mathrm{Ag} / \mathrm{ml}$ streptomycin in a humidified $\mathrm{CO}_{2}$ incubator at $37^{\circ} \mathrm{C}$.

All specimens were obtained from the General Surgery Department of The Second Affiliated Hospital of Dalian Medical University (Liaoning, China) and included 101 samples of follicular thyroid cancer and the corresponding peritumoral tissues ( $3 \mathrm{~cm}$ from the tumor edge). For the use of these clinical materials for research purposes, prior consents from the patients and approval from the Ethics Committees of The Second Affiliated Hospital of Dalian Medical University were obtained, and all the procedures have been performed in compliance with the Helsinki Declaration. All specimens had confirmed pathological diagnosis and were staged according to the 2013 thyroid carcinomas staging system of the International Union against Cancer (UICC). These tissues were snap-frozen in liquid nitrogen and stored at $-80^{\circ} \mathrm{C}$ until used.

RNA isolation and real-time PCR analysis. Real-time PCR was used to analyze gene expression. Total RNA was isolated using the RNeasy Mini kit (Qiagen, Valencia, CA, USA), and cDNA was synthesized using the QuantiTect Reverse Transcription kit (Qiagen) according to the manufacturer's protocol. Real-time PCR was carried out on an ABI Prism 7500 Fast Real-Time PCR system (Applied Biosystems, Foster City, CA, USA) using QuantiTect SYBR Green PCR kit (Qiagen). The primer sequences used for amplification were as follows: forward, 5'-CTTTGCCCTGTACTTCTCG-3' and reverse, 5'-CAGCACTGGAATGGAGAGA-3' for ST6GalNAcII; and forward, 5'-CTCCTCCACCTTTGACGCTG-3' and reverse, 5'-TCCTCTTGTGCTCTTGCTGG-3' for GAPDH. The relative expression level of target gene was normalized to that of the respective GAPDH.

Western blot analysis. Extracted proteins were electrophoresed under reducing conditions in $10 \%$ sodium dodecylsulfate-polyacrylamide gels, and then blotted onto a polyvinylidene difluoride membrane. After blocking with 5\% skimmed milk in PBS containing 0.1\% Tween-20 (PBST), the membrane was incubated with antibody $(1 / 1,000$ diluted; Abcam) and then with peroxidase-conjugated antirabbit IgG (1/10,000 diluted; GE Healthcare UK Ltd., Little Chalfont, UK). A GAPDH antibody (1/200 diluted; Santa Cruz Biotechnology) was used as a control. All bands were detected using ECL Western Blot kit (Amersham Biosciences,
UK), and the bands were analyzed with LabWorks ${ }^{\mathrm{TM}}$ (ver 4.6, UVP; Bio-Imaging Systems).

Deregulation of ST6GalNAcII by RNAi. FTC-238 cells were incubated in appropriate antibiotic-free medium with $10 \%$ fetal bovine serum (Gibco), transferred to a 6 -well tissue culture, and incubated at $37^{\circ} \mathrm{C}$ in a $\mathrm{CO}_{2}$ incubator to obtain $60-80 \%$ confluence. The cell cultures were stably co-transfected with a plasmid vector containing the puromycin-resistance marker and the specific short hairpin RNA (shRNA) (ST6GalNAcII), respectively, which was prepared according to the protocol. Scrambled shRNA was used as the negative control. The transfection efficiency calculated by the percentage of fluorescent cells was about $82 \%$, and cell viability was $89 \%$ by trypan blue dye exclusion assay. Four weeks later, we used puromycin to screen the cells stably expressing shRNA. Several colonies were picked and expanded for further study. The knockdown had no effects on the cell morphology.

Overexpression of ST6GalNAcII. The human ST6GalNAcII coding sequences were obtained from Takara Company (Dalian, China) and were inserted into the pEGFP-N2 vector (Invitrogen, Carlsbad, CA, USA) at the sites of EcoRI, XhoI. Cells were transfected with $5 \mu \mathrm{g}$ of target gene expression vector or empty vector (EV) in 100-mm dishes using PolyFect transfection reagent (Qiagen) according to the manufacturer's instruction. After 4 weeks of screening, the cell lines stably expressing ST6GalNAcII (FTC-133/ST6GalNAcII) and empty vector (FTC-133/mock) were established. Then cells were collected for gene expression assay and for further explorations. The cell transfection efficiency was $79 \%$ and the survival rate was $87 \%$.

In vitro extracellular matrix invasion assays. Invasiveness of tumor cells was examined using 24-well Transwell units (Corning, Corning, NY, USA) with 8-mm pore size polycarbonate filter coated with Matrigel (BD Biosciences) to form a continuous thin layer. Cells $\left(3 \times 10^{5}\right)$ were harvested in serum-free medium containing $0.1 \%$ BSA and added to the upper chamber. The lower chamber contained $500 \mathrm{ml} 90 \%$ RPMI-1640 and 10\% FBS. At the end of incubation, the cells on the upper surface of the filter were completely removed by wiping with a cotton swab. The filters were fixed in methanol and stained with Wright-Giemsa. Cells invading the Matrigel that reached the lower surface of the filter were counted with light microscope at a magnification of $x 400$. In migration assay, the upper chamber was not coated with Matrigel. Samples were acquired in triplicate and data expressed as the average cell number in five fields.

In vivo tumorigenicity assay. The tumorigenicity of ST6GalNAcII in vivo was investigated using a xenograft tumor model in the nude mice. Forty-eight 5-week-old male athymic nude mice were provided with sterilized food and water and equally divided into three groups. Approximately, $1 \times 10^{7}$ cells (with or without ST6GalNAcII shRNA interference and control shRNA) were subcutaneously inoculated into the right flank of each nude mouse. Once bearing palpable tumors (about 4 weeks after tumor cell inoculation), mice 

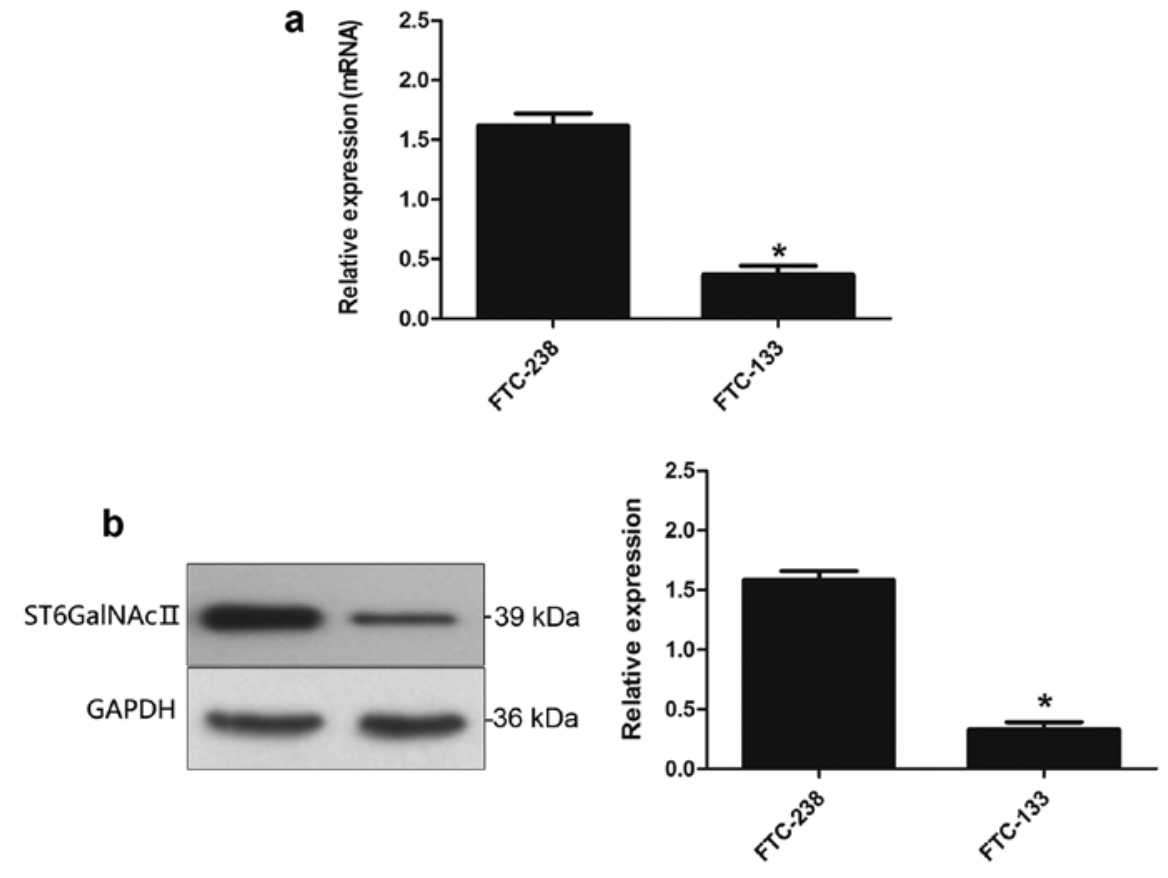

Figure 1. Differential expression of ST6GalNAcII in FTC-238 cell lines and FTC-133 cell lines. (a) The mRNA level of ST6GalNAcII was analyzed by realtime PCR. Slight difference was observed in the level of ST6GalNAcII mRNA ("P<0.05). (b) Western blot analysis of ST6GalNAcII gene at protein levels. ST6GalNAcII gene was more abundant in FTC-238 cells than FTC-133. GAPDH served as a control. Data are the means \pm SD of triplicates ("P<0.05).

were sacrificed and their tumors were isolated, weighed, and photographed. Experiments were repeated three times.

Inhibition of the PI3K/Akt signaling. LY294002 (Sigma) was used to suppress the activity of the PI3K/Akt signaling in FTC-238 cells. Briefly, the tumor cells $\left(1 \times 10^{4}\right.$ cells/well) were incubated with dimethyl sulfoxide (DMSO) or the PI3K inhibitor LY294002 (20 mmol/l) dissolved in DMSO, and collected after $24 \mathrm{~h}$. Tumorigenicity was analyzed when PI3K/Akt signaling was blocked in xenograft tumor model. Sixty female athymic nude mice (5-week-old) were divided into 4 groups and $1 \times 10^{7}$ FTC-238 cells (with DMSO, LY294002, control shRNA, Akt shRNA, respectively) were injected subcutaneously into the axillary regions of each nude mouse, respectively. Once bearing palpable tumors (about 4 weeks after tumor cell inoculation), mice were sacrificed and their tumors were isolated and weighed. Changes in protein expression were measured by western blot analysis.

Immunohistochemical (IHC) staining analysis. Tumors were removed from the mice and immunohistochemical (IHC) staining was conducted using formalin-fixed paraffin-embedded sections of tissues by the avidin-biotin-peroxidase complex (ABC) method. Four-micron sections of formalin-fixed paraffin-embedded tissues were cut with a microtome and dried overnight at $37^{\circ} \mathrm{C}$ on a silicanized slide (Dako, Carpinteria, CA, USA). Samples were deparaffinized in xylene at room temperature for $80 \mathrm{~min}$ and washed with a graded ethanol/water mixture and then with distilled water. The samples were soaked in a citrate buffer and then microwaved at $100^{\circ} \mathrm{C}$ for $10 \mathrm{~min}$. The following steps were used. Before addition of the primary antibodies, endogenous peroxidase activity was blocked by incubation in methanol containing $1 \% \mathrm{H}_{2} \mathrm{O}_{2}$ for $20 \mathrm{~min}$, followed by $60 \mathrm{~min}$ incubation with normal donkey serum to reduce background staining. The primary antibodies, goat antihuman, ST6GalNAcII antibodies (Abcam, Cambridge, UK), were incubated at $4^{\circ} \mathrm{C}$ for $8 \mathrm{~h}$, followed by incubation with the biotinylated secondary antibodies (donkey anti-goat IgG; Santa Cruz Biotechnology) for $30 \mathrm{~min}$ and ABC complex for $30 \mathrm{~min}$. The primary and secondary antibodies were used at 1:80 and 1:100 dilutions, respectively. The peroxidase binding sites were demonstrated by the diaminobenzidine method. A phosphatebuffered solution instead of the primary antibody was used in the protocols for negative controls. The level of expression level is measured by Image-Pro Plus software 6.0.

Statistical analysis. Each experiment was performed at least in triplicate, and the measurements were performed in three independent experiments. The data were expressed as mean \pm standard deviation (SD) from the triple tests of each group. SPSS 17.0 software was used for statistical analysis and Student's t-test was selected to determine the significance of differences among the examined groups. $\mathrm{P}<0.05$ was considered to be statistically significant.

\section{Results}

Differential expression of ST6GalNAcII in follicular thyroid carcinoma cell lines. Real-time PCR and western blot analysis was used to evaluate the expression level of ST6GalNAcII in mRNA (Fig. 1a) and protein expression (Fig. 1b). These data indicated that ST6GalNAcII may be associated with metastasis of human follicular thyroid carcinoma cells (FTC-238).

Silence of ST6GalNAcII inhibits the invasive ability of follicular thyroid cancer cells in vitro and in vivo. Owing to the high expression of ST6GalNAcII in FTC-238 cells, we silenced ST6GalNAcII with shRNA, in order to elucidate 


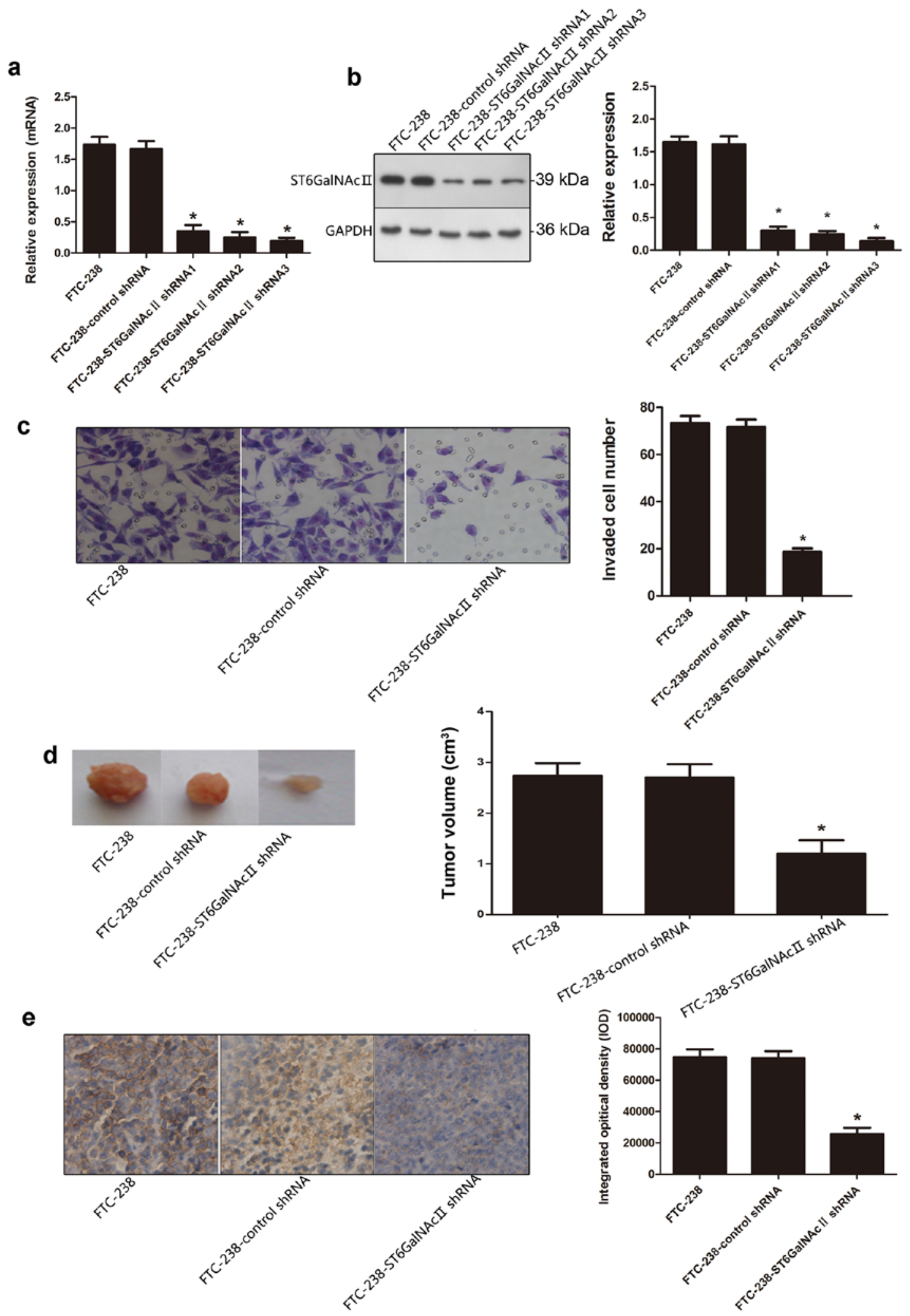

Figure 2. Silence of ST6GalNAcII gene inhibits the invasive ability of FTC-238 cells both in vitro and in vivo. (a and b) Silencing of ST6GalNAcII in FTC-238 cells was analyzed by RNAi approach. After shRNA transfection, distinct reduction of ST6GalNAcII was observed at protein levels by real-time PCR and western blot analysis. (c) The average number of cells that invaded through the filter was assessed by ECMatrix gel analysis in vitro. FTC-238-ST6GalNAcII shRNA cells were significantly less invasive ("P<0.05) than the FTC-238 cells and FTC-238-control shRNA cells. (d) A decrease of mean tumor volume in mouse group with FTC-238-ST6GalNAcII shRNA1 tumors was observed, as compared to the control group ("P<0.05). (e) Downregulation of ST6GalNAcII was also shown by IHC staining in xenograft tumors derived from FTC-238-ST6GalNAcII shRNA1 cells ( $x 400)($ ( $P<0.05)$. Data are the means \pm SD of triplicates $\left({ }^{*} \mathrm{P}<0.05\right)$.

the effect of ST6GalNAcII on the invasion and metastasis of thyroid cancer cells. As shown in Fig. 2a and b, the expression level of ST6GalNAcII was significantly reduced in FTC-238 transfectants compared to the control transfectants $(\mathrm{P}<0.05)$. 


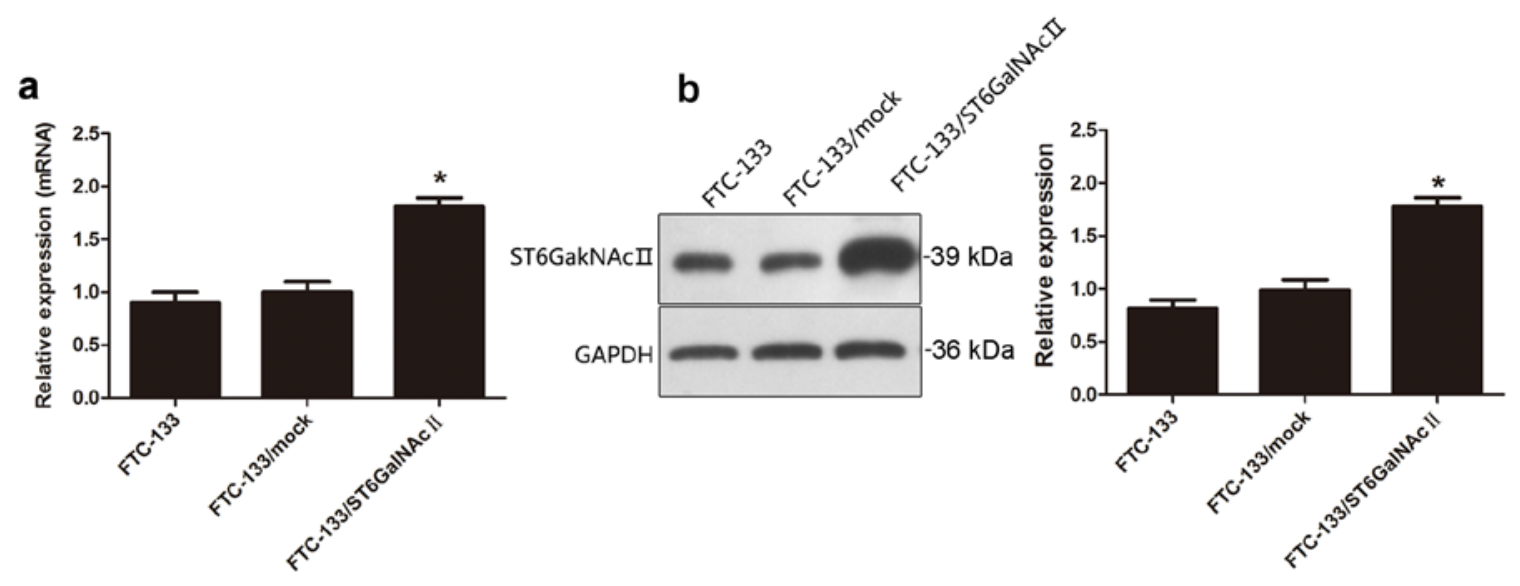

C
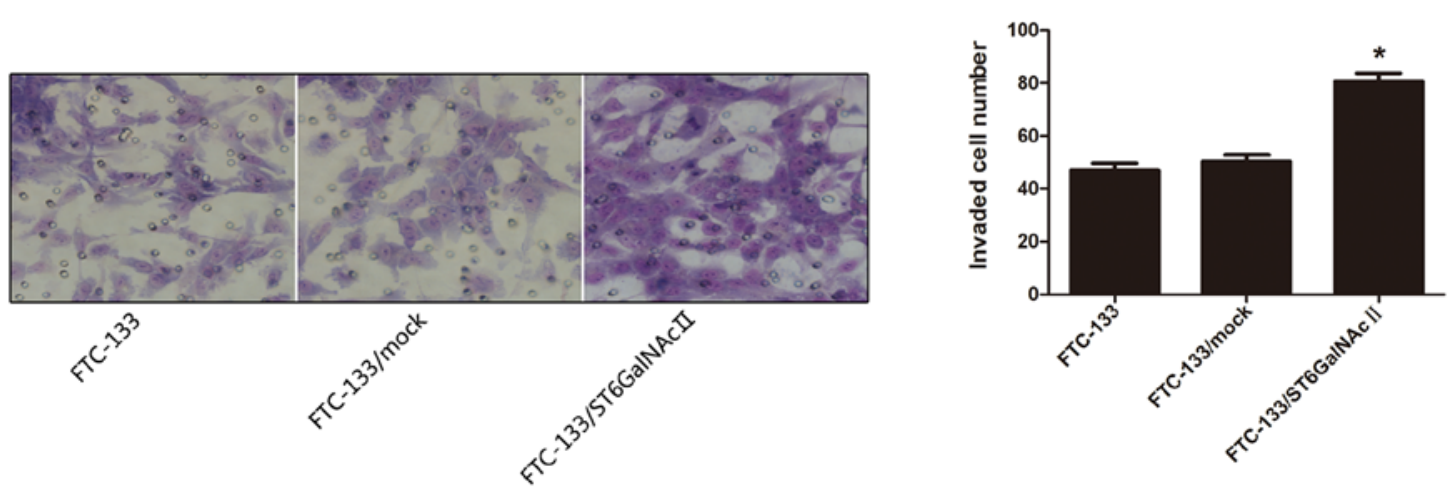

d

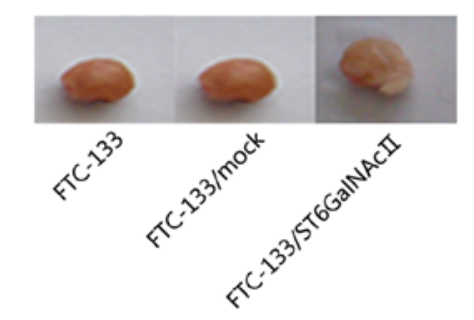

e
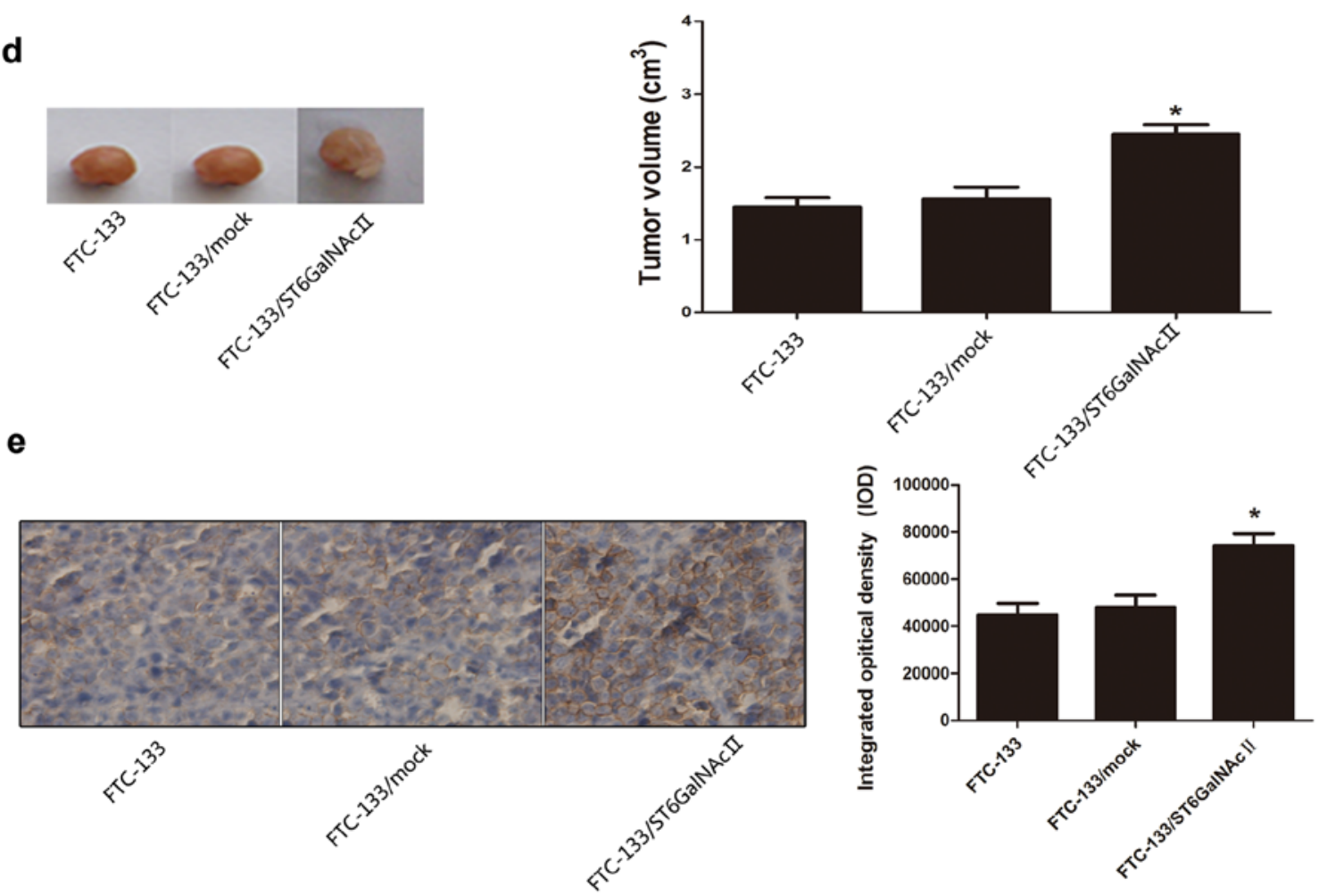

Figure 3. Overexpression of ST6GalNAcII gene enhances the invasive ability of FTC-133 cells both in vitro and in vivo. (a and b) After full-length sequence transfection, ST6GalNAcII mRNA and protein were increased notably in FTC-133 cells by real-time PCR and western blotting. (c) The invasiveness of cells was analyzed. FTC-133/ ST6GalNAcII cells were significantly more invasive ( $\left.{ }^{*} \mathrm{P}<0.05\right)$ than the FTC-133 and FTC-133/mock cells. (d) Tumor volumes were increased obviously in nude mice bearing FTC-133/ST6GalNAcII, as compared to the control group ("P<0.05). (e) Upregulation of ST6GalNAcII was also shown by IHC staining in xenograft tumors derived from FTC-133/ST6GalNAcII cells $(x 400)(" \mathrm{P}<0.05)$. Data are the means \pm SD of triplicate determinants $\left({ }^{*} \mathrm{P}<0.05\right)$.

After ST6GalNAcII shRNA transfection, Transwell invasion assay was performed to further evaluate the inva- sion capability of cells with ST6GalNAcII knockdown on tumor cells in vitro. The invasion capability of FTC-238 cells 

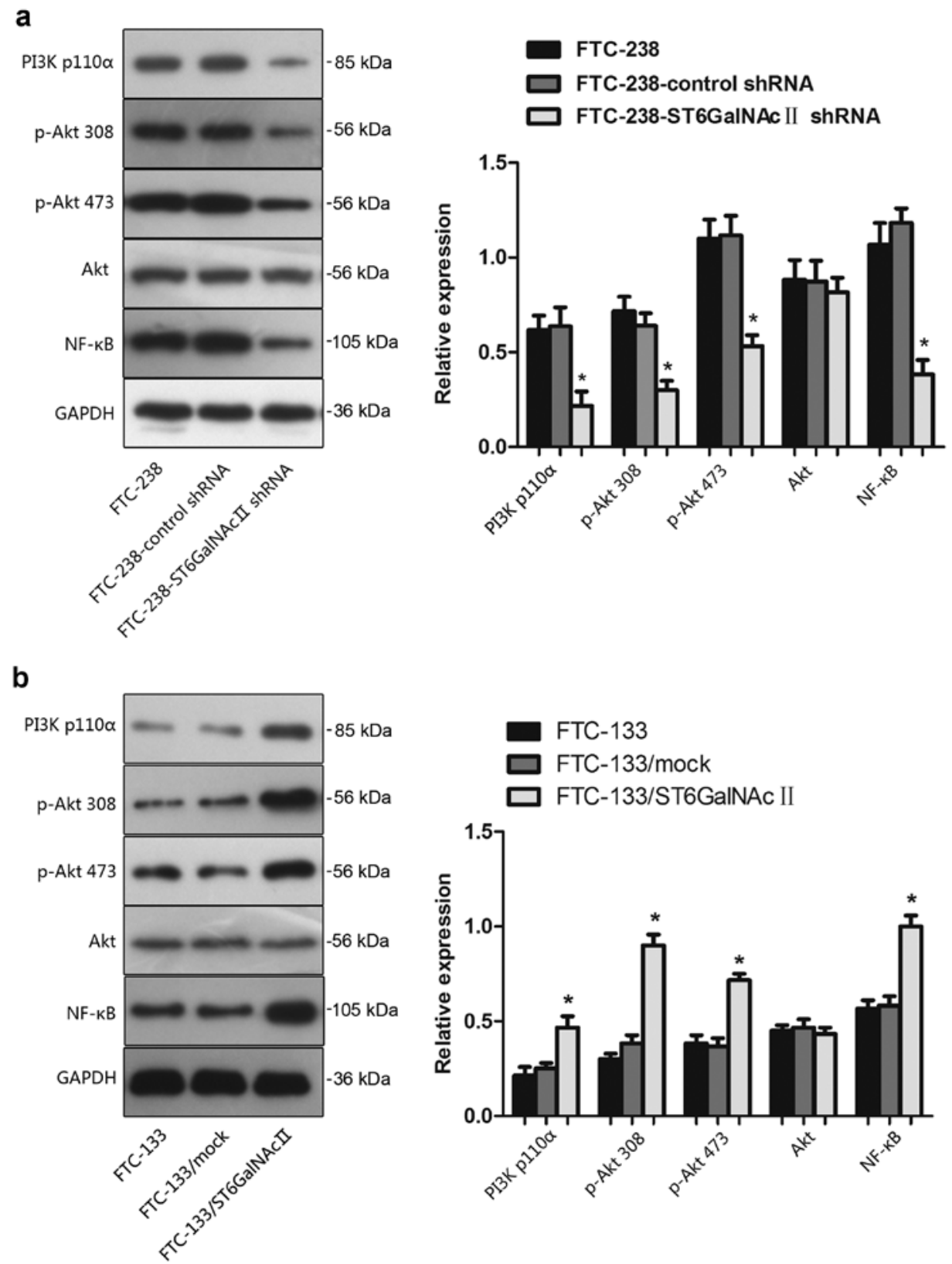

Figure 4. ST6GalNAcII gene mediates the activity of PI3K/Akt signaling pathway in FTC-238 and FTC-133 cell lines. (a) Expression of PI3K/Akt/NF- $\kappa B$ signaling molecules were downregulated at protein levels with ST6GalNAcII shRNA1 transfection in FTC-238-ST6GalNAcII shRNA1 cells ("P<0.05). (b) The increased protein levels of PI3K/Akt/NF-kB signaling molecules were determined by western blotting in FTC-133/ST6GalNAcII cells ("P<0.05). Data are the means \pm SD of triplicates $(" \mathrm{P}<0.05)$.

transfected with ST6GalNAcII shRNA showed a significant reduction, as compared with control shRNA group, suggesting that cell invasion capability was inhibited by treatment with ST6GalNAcII shRNA (Fig. 2c).

Nude mice bearing FTC-238, FTC-238-control shRNA and FTC-238-ST6GalNAcII shRNA1 xenografts were used to analyze the differences by measuring tumor volumes. Fig. $2 \mathrm{~d}$ showed a significant reduction of mean tumor volume in nude mice bearing FTC-238-ST6GalNAcII shRNA, as compared with control shRNA group.

IHC staining analysis of the tumor section revealed that ST6GalNAcII was reduced in tumors derived from FTC-238-ST6GalNAcII shRNA cells compared to control group (Fig. 2e).
The above results indicated that knockdown of ST6GalNAcII could inhibit the invasion ability of follicular thyroid carcinoma cells.

Overexpression of ST6GalNAcII enhances the invasive ability of follicular thyroid cancer cells in vitro and in vivo. After elucidating whether the effect of ST6GalNAcII suppresses the invasion ability of FTC-238, we transfected FTC-133 cells with ST6GalNAcII expression vector to determine the effect of overexpression of ST6GalNAcII on tumor cell invasion ability of FTC-133. As shown in Fig. 3a and b, increased levels of mRNA and protein of were detected in FTC-133 transfectants.

Transwell invasion assay revealed that the invasion capability of FTC-133 cells transfected with ST6GalNAcII 
a

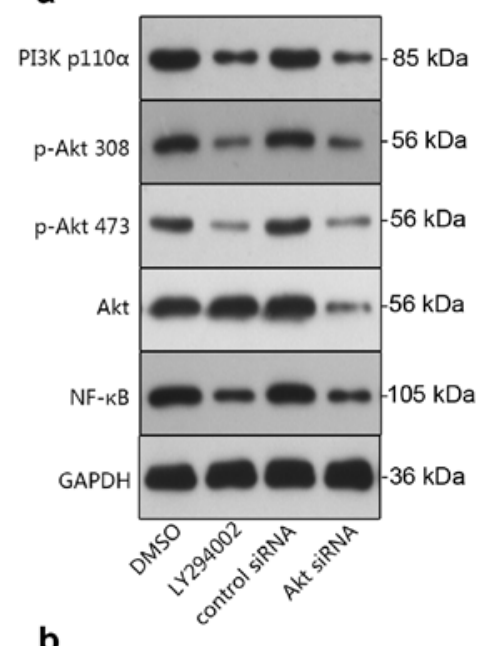

b
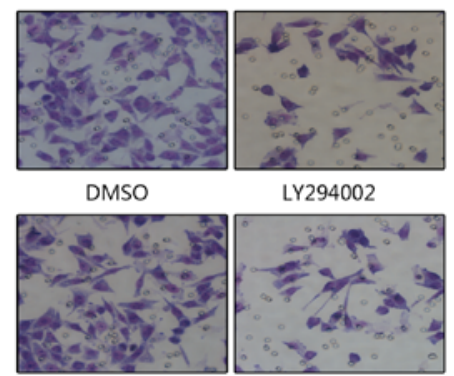

control siRNA

Akt siRNA

C

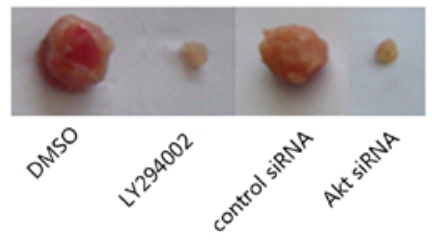

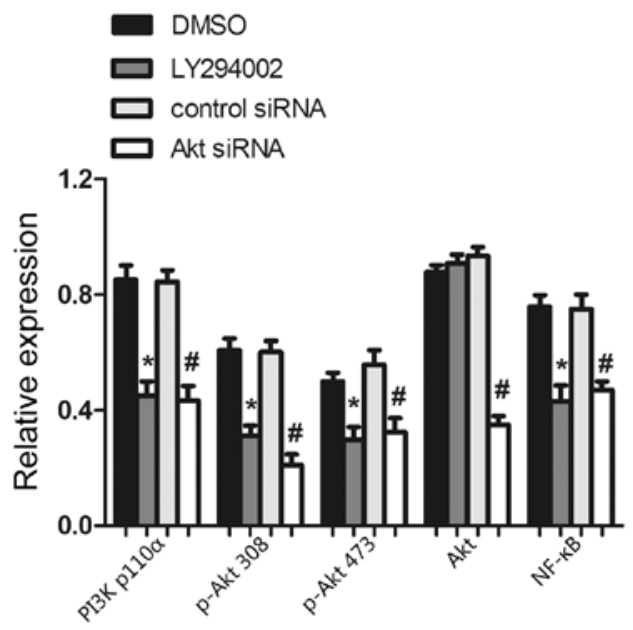
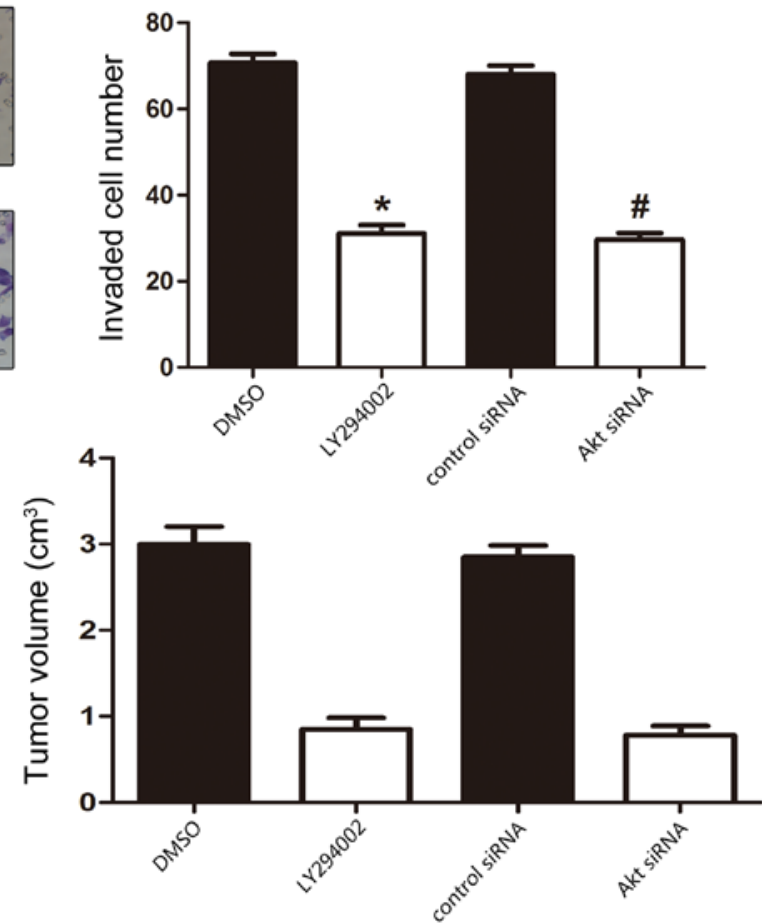

Figure 5. PI3K/Akt inhibition modulates the invasive ability of FTC-238 cells both in vitro and in vivo. (a) The FTC-238 cells were pretreated with LY294002 or Akt siRNA. Expression of PI3K/Akt/NF-kB signaling molecules were then examined by western blot analysis. (b) LY294002 or Akt siRNA treatment decreased the invasive ability of FTC-238 cells in vitro. (c) Downregulation of PI3K/Akt/NF- $\mathrm{KB}$ signaling molecules was also shown by IHC staining in xenograft tumors derived from LY294002 or Akt shRNA treated cells (x400). ${ }^{*} \mathrm{P}<0.05$ vs. DMSO treated cells; ${ }^{\#} \mathrm{P}<0.05$ vs. control siRNA treatment cells. Data are the means $\pm \mathrm{SD}$ of triplicate determinants $($ " $\mathrm{P}<0.05)$.

expression vector was obviously increased compared with the FTC-133/mock cells (Fig. 3c).

Nude mice were inoculated with tumor cells FTC-133, FTC-133/mock, and FTC-133/ST6GalNAcII. Tumor volumes were increased obviously in nude mice bearing FTC-133/ST6GalNAcII, as compared to the FTC-133/mock group (Fig. 3d).

High expression levels of ST6GalNAcII in tumor cells of FTC-133/ST6GalNAcII, was also detected using IHC staining, as shown in Fig. 3e.

Therefore, the upregulation of the ST6GalNAcII gene was able to increase the invasion ability of follicular thyroid carcinoma cells.
ST6GalNAcII regulates the activity of PI3K/Akt signaling pathway in thyroid cells. Having established the pivotal role of PI3K/Akt pathway in tumor cells, we investigated whether ST6GalNAcII activated the PI3K/Akt pathway and whether this pathway played a central role in ST6GalNAcII-mediated cell invasion. Fig. 4a shows that following the decreased expression level of ST6GalNAcII, the expression and activity of the PI3K/Akt pathway was inhibited. PI3K expression decreased the protein and phosphorylation levels of Akt. The degree of phosphorylation of Akt at Ser473 and Thr308 and its downstream effector $\mathrm{NF}-\kappa \mathrm{B}$ was also downregulated after ST6GalNAcII silencing. No variation could be detected in the total amount of Akt protein, indicating a true decrease in the 
Table I. Correlation between the clinicopathological characteristics and expression of ST6GalNAcII protein in thyroid carcinoma.

\begin{tabular}{|c|c|c|c|c|}
\hline \multirow[b]{2}{*}{ Characteristics } & \multirow[b]{2}{*}{$\mathrm{n}$} & \multicolumn{2}{|c|}{ ST6GalNAcII } & \multirow[b]{2}{*}{ P-value } \\
\hline & & ST6GalNAcII(high) (\%) & ST6GalNAcII(low) (\%) & \\
\hline \multicolumn{5}{|l|}{ Group } \\
\hline Cancer tissue & 101 & $73(72.3)$ & $28(27.3)$ & 0.004 \\
\hline Pericarcinomatous tissues & 101 & $53(52.5)$ & $48(47.5)$ & \\
\hline \multicolumn{5}{|l|}{ Age (years) } \\
\hline$\geq 50$ & 35 & $20(57.1)$ & $15(42.9)$ & 0.736 \\
\hline$<50$ & 66 & $40(60.6)$ & $26(39.4)$ & \\
\hline \multicolumn{5}{|l|}{ Histological grade } \\
\hline G1 & 75 & $33(44.0)$ & $42(56.0)$ & 0.004 \\
\hline G2, G3 & 26 & $20(76.9)$ & $6(23.1)$ & \\
\hline \multicolumn{5}{|l|}{ Lymph node metastasis } \\
\hline Absent & 49 & $23(46.9)$ & $26(53.1)$ & 0.002 \\
\hline Present & 52 & $40(76.9)$ & $12(23.1)$ & \\
\hline \multicolumn{5}{|l|}{ Distant metastasis } \\
\hline Yes & 19 & $14(73.7)$ & $5(26.3)$ & 0.112 \\
\hline No & 82 & $44(53.7)$ & $38(46.3)$ & \\
\hline \multicolumn{5}{|l|}{ Clinical stage } \\
\hline I-II & 45 & $20(44.4)$ & $25(55.6)$ & 0.006 \\
\hline III-IV & 56 & $40(71.4)$ & $16(28.6)$ & \\
\hline
\end{tabular}

phosphorylation status. In addition, as illustrated in Fig. 4b, over-expression of ST6GalNAcII in FTC-133 cells showed the reverse tendency. The above suggested that the variation of ST6GalNAcII expression levels alters the PI3K/Akt signaling pathway.

PI3K/Akt inhibition mediates the invasion ability of FTC-238 cells both in vitro and in vivo. After inhibition of PI3K and Akt by LY294002 and Akt siRNA, the invasion ability was significantly inhibited in FTC-238 cells. By western blotting, FTC-238 cells treated with LY294002, and Akt siRNA treatment exhibited apparently decreased expression levels of the main signal molecules of PI3K/Akt pathway (Fig. 5a). As shown in Fig. 5b, the inhibition of PI3K/Akt pathway made the FTC-238 cells less invasive. In Transwell invasion assay, the invasive capability of FTC-238 cells transfected with Akt siRNA obviously decreased in the Transwell migration and invasion assay. Similar results were also observed in vivo analysis where reduced tumor weight was measured in the mouse group bearing FTC-238 tumors with impaired PI3K/Akt signaling (Fig. 5b). Altered expression levels of the main signal molecules of the PI3K/Akt pathway in the mouse group bearing FTC-238 tumors with LY294002 or Akt shRNA treatment were also validated using IHC staining. These data implicated a role of PI3K/Akt signaling in regulating the invasive properties of FTC-238 cells.

Clinical implications of ST6GalNAcII expression in thyroid carcinoma. The ST6GalNAcII expression status was detected in thyroid cancer with the corresponding pericarcinomatous tissue samples by immunohistochemistry staining (Table I).
The data as shown in Table I are number of cases, and the expression of ST6GalNAcII was classified as high if $>30 \%$ of tumor cells are stained and as low if $<30 \%$ of cancer cells were stained. It is shown that follicular thyroid cancer tissues had a higher expression level of ST6GalNAcII compared with transitional tissues $(\mathrm{P}=0.004)$. There was no significant association between ST6GalNAcII expression and age, or distant metastasis in follicular thyroid carcinoma patients $(\mathrm{P}>0.05)$. Interestingly, the expression of ST6GalNAcII was also closely correlated with histological grade, lymph node metastasis, and clinical stage $(\mathrm{P}=0.004,0.002,0.006$, respectively).

\section{Discussion}

Metastasis remains the major cause of mortality and relapse for most solid malignancies. Some research is currently underway to identify the signaling pathways and molecular mechanisms of metastasis in thyroid cancer (19-22). In this study, we investigated the expression of ST6GalNAcII, via PI3K/Akt signaling pathway, to assess whether it effectively regulated the invasiveness of follicular thyroid carcinoma cell lines FTC-238 (lung metastasis) and FTC236 (lymph node metastasis) and FTC-133 (primary tumor). We further analyzed the differential expression of ST6GalNAcII, which was reported to be related with clinicopathological characteristics of human follicular thyroid cancer.

Alteration in the expression pattern of glycogens is correlated with the invasive potential of various types of cancer $(23,24)$. The biosynthetic pathway of sialylated glycans highlights the importance of sialyltransferases. Using real-time PCR analysis, we revealed that the expression profile 
of ST6GalNAcII gene was remodeled between FTC-238 and FTC-133 and FTC-236. As depicted in Fig. 1a, FTC-238 cells showed a higher expression of ST6GalNAcII mRNA compared to FTC-133 and FTC-236 cells. This result suggested that ST6GalNAcII gene was active in the cells with high metastatic potential. Our previous report also indicated the crucial role of ST6GalNAcII gene in promoting high metastatic potential cell invasion in breast carcinoma (25). The altering expression of ST6GalNAcII gene in the two follicular thyroid cell lines may be more important as indicators and functional regulators of tumor metastasis.

Recent findings show that the overactivation of the PI3K/Akt signaling pathway plays a crucial role in regulating tumor invasive ability $(26,27)$. We investigated the molecular mechanism by which ST6GalNAcII-mediated PI3K/Akt signaling pathway regulates follicular thyroid cancer cells invasiveness. Our study explored a novel mechanism that the invasion and chemosensitivity of human hepatocarcinoma cells can be regulated by the activation of ST6GAL1 or ST8SIA2-mediated PI3K/Akt (28). In this study, we indicated that ST6GalNAcII exerts the role of tumor metastasis of human follicular thyroid carcinoma through activation of the PI3K/Akt/NF- $\kappa \mathrm{B}$ signal pathway. We demonstrated that FTC-238 cells exhibited higher PI3K/Akt activity than FTC-133. In addition, the invasive properties of FTC-238 cells were reversed by the inhibition of the PI3K/Akt pathway (Fig. 2e). These results indicated that ST6GalNAcIImodulated follicular thyroid carcinoma cell invasion was, at least in part, PI3K/Akt-dependent.

With altered mRNA expression in carcinoma tissues, sialyltransferases are regarded as prognostic factors and potential targets for therapeutic approaches $(29,30)$. In this study, we utilized immunohistochemistry to evaluate protein expression of ST6GalNAcII in follicular thyroid cancer specimens of 101 cases. The result illustrated that follicular thyroid cancer tissues had a higher expression level of ST6GalNAcII than in the normal thyroid tissues (Table I). In addition, we found the expression of ST6GalNAcII was associated with histological grade, lymph node metastasis and clinical stage (Table I). The results from the clinical samples indicated that the altered level of ST6GalNAcII may play an important role in promoting invasion and metastasis of follicular thyroid cancer. Furthermore, it may be possible to utilize ST6GalNAcII as a useful biomarker for clinical diagnosis of thyroid cancer metastasis.

In conclusion, our work reveals differential expression of ST6GalNAcII gene in two human follicular thyroid carcinoma cell lines and follicular thyroid cancer specimens. ST6GalNAcII elucidated the unusual properties of invasion in thyroid cancer cells via modulating the PI3K/AKt signaling pathway. Besides, the elevated expression of ST6GalNAcII was associated with histological grade, lymph node metastasis and clinical stage of follicular thyroid cancer. Seeking for agents that simultaneously inhibit ST6GalNAcII gene may be a promising strategy for blocking follicular thyroid carcinoma metastasis in patients.

\section{References}

1. Dall'Olio F and Chiricolo M: Sialyltransferases in cancer. Glycoconj J 18: 841-850, 2001.
2. Harvey BE, Toth CA, Wagner HE, Steele GD Jr and Thomas P: Sialyltransferase activity and hepatic tumor growth in a nude mouse model of colorectal cancer metastases. Cancer Res 52. 1775-1779, 1992.

3. Majuri ML, Niemelä R, Tiisala S, Renkonen $\mathrm{O}$ and Renkonen R: Expression and function of alpha 2,3-sialyl- and alpha 1,3/1,4-fucosyltransferases in colon adenocarcinoma cell lines: Role in synthesis of E-selectin counter-receptors. Int J Cancer 63: 551-559, 1995.

4. Yogeeswaran G and Salk PL: Metastatic potential is positively correlated with cell surface sialylation of cultured murine tumor cell lines. Science 212: 1514-1516, 1981.

5. Dennis J, Waller C, Timpl R and Schirrmacher V: Surface sialic acid reduces attachment of metastatic tumour cells to collagen type IV and fibronectin. Nature 300: 274-276, 1982.

6. Ohtsubo K and Marth JD: Glycosylation in cellular mechanisms of health and disease. Cell 126: 855-867, 2006.

7. Kim YJ, Kim KS, Kim SH, Kim CH, Ko JH, Choe IS, Tsuji S and Lee YC: Molecular cloning and expression of human Gal beta 1,3GalNAc alpha 2,3-sialytransferase (hST3Gal II). Biochem Biophys Res Commun 228: 324-327, 1996.

8. Harduin-Lepers A, Mollicone R, Delannoy P and Oriol R: The animal sialyltransferases and sialyltransferase-related genes: A phylogenetic approach. Glycobiology 15: 805-817, 2005.

9. Takashima S, Tsuji S and Tsujimoto M: Characterization of the second type of human beta-galactoside alpha 2,6-sialyltransferase (ST6Gal II), which sialylates Galbeta 1,4GlcNAc structures on oligosaccharides preferentially. Genomic analysis of human sialyltransferase genes. J Biol Chem 277: 45719-45728, 2002.

10. Julien S, Adriaenssens E, Ottenberg K, Furlan A, Courtand G, Vercoutter-Edouart AS, Hanisch FG, Delannoy $P$ and Le Bourhis X: ST6GalNAc I expression in MDA-MB-231 breast cancer cells greatly modifies their $\mathrm{O}$-glycosylation pattern and enhances their tumourigenicity. Glycobiology 16: 54-64, 2006.

11. Ding JX, Xu LX, Zhu L, Lv JC, Zhao MH, Zhang $\mathrm{H}$ and Wang HY: Activity of $\alpha 2,6$-sialyltransferase and its gene expression in peripheral B lymphocytes in patients with $\operatorname{Ig} \mathrm{A}$ nephropathy. Scand J Immunol 69: 174-180, 2009.

12. Xu LX and Zhao MH: Aberrantly glycosylated serum IgA1 are closely associated with pathologic phenotypes of IgA nephropathy. Kidney Int 68: 167-172, 2005.

13. Reticker-Flynn NE and Bhatia SN: Aberrant glycosylation promotes lung cancer metastasis through adhesion to galectins in the metastatic niche. Cancer Discov 5: 168-181,2015.

14. Bos PD, Zhang XH, Nadal C, Shu W, Gomis RR, Nguyen DX, Minn AJ, van de Vijver MJ, Gerald WL, Foekens JA, et al: Genes that mediate breast cancer metastasis to the brain. Nature 459: 1005-1009, 2009

15. Engelman JA, Luo J and Cantley LC: The evolution of phosphatidylinositol 3-kinases as regulators of growth and metabolism. Nat Rev Genet 7: 606-619, 2006.

16. Bellacosa A, Kumar CC, Di Cristofano A and Testa JR: Activation of AKT kinases in cancer: Implications for therapeutic targeting. Adv Cancer Res 94: 29-86, 2005.

17. Tamburrino A, Molinolo AA, Salerno P, Chernock RD, Raffeld M, Xi L, Gutkind JS, Moley JF, Wells SA Jr and Santoro M: Activation of the mTOR pathway in primary medullary thyroid carcinoma and lymph node metastases. Clin Cancer Res 18: 3532-3540, 2012.

18. Xu X, Qin J and Liu W: Curcumin inhibits the invasion of thyroid cancer cells via down-regulation of PI3K/Akt signaling pathway. Gene 546: 226-232, 2014

19. Vu-Phan D, Grachtchouk V, Yu J, Colby LA, Wicha MS and Koenig RJ: The thyroid cancer PAX8-PPARG fusion protein activates Wnt/TCF-responsive cells that have a transformed phenotype. Endocr Relat Cancer 20: 725-739, 2013.

20. Milosevic Z, Pesic M, Stankovic T, Dinic J, Milovanovic Z, Stojsic J, Dzodic R, Tanic N and Bankovic J: Targeting RAS-MAPK-ERK and PI3K-AKT-mTOR signal transduction pathways to chemosensitize anaplastic thyroid carcinoma. Transl Res 164: 411-423, 2014.

21. Geraldo MV, Yamashita AS and Kimura ET: MicroRNA miR-146b-5p regulates signal transduction of TGF- $\beta$ by repressing SMAD4 in thyroid cancer. Oncogene 31: 1910-1922, 2012.

22. Soula-Rothhut M, Coissard C, Sartelet H, Boudot C, Bellon G, Martiny L and Rothhut B: The tumor suppressor PTEN inhibits EGF-induced TSP-1 and TIMP-1 expression in FTC-133 thyroid carcinoma cells. Exp Cell Res 304: 187-201, 2005. 
23. Sawada M, Moriya S, Saito S, Shineha R, Satomi S, Yamori T, Tsuruo T, Kannagi R and Miyagi T: Reduced sialidase expression in highly metastatic variants of mouse colon adenocarcinoma 26 and retardation of their metastatic ability by sialidase overexpression. Int J Cancer 97: 180-185, 2002.

24. Lin S, Kemmner W, Grigull S and Schlag PM: Cell surface alpha 2,6 sialylation affects adhesion of breast carcinoma cells. Exp Cell Res 276: 101-110, 2002.

25. Ren D, Jia L, Li Y, Gong Y, Liu C, Zhang X, Wang N and Zhao Y: ST6GalNAcII mediates the invasive properties of breast carcinoma through PI3K/Akt/NF- $\kappa \mathrm{B}$ signaling pathway. IUBMB Life 66: 300-308, 2014.

26. Zhou F, Cui C, Ge Y, Chen H, Li Q, Yang Z, Wu G, Sun S, Chen K, Gu J, et al: Alpha2,3-Sialylation regulates the stability of stem cell marker CD133. J Biochem 148: 273-280, 2010.
27. Li Z: CD133: A stem cell biomarker and beyond. Exp Hematol Oncol 2: 17, 2013.

28. Zhao Y, Li Y, Ma H, Dong W, Zhou H, Song X, Zhang J and Jia L: Modification of sialylation mediates the invasive properties and chemosensitivity of human hepatocellular carcinoma. Mol Cell Proteomics 13: 520-536, 2014.

29. López-Morales D, Velázquez-Márquez N, Valenzuela O, Santos-López G, Reyes-Leyva J and Vallejo-Ruiz V: Enhanced sialyltransferases transcription in cervical intraepithelial neoplasia. Invest Clin 50: 45-53, 2009.

30. Wang PH, Lee WL, Juang CM, Yang YH, Lo WH, Lai CR, Hsieh SL and Yuan CC: Altered mRNA expressions of sialyltransferases in ovarian cancers. Gynecol Oncol 99: 631-639, 2005. 